\title{
Shortcuts: \\ A Visualization of Interactive Processes
}

\author{
Ilana Paterman \\ Escola Superior de Desenho Industrial, \\ Universidade do Estado do Rio de Janeiro, Brazil \\ http://www.esdi.uerj.br
}

\begin{abstract}
Shortcuts is a critical design contribution to suggest us to think about interactive processes, regarding immediateness and automation promoted by digital technologies. A video illustrates this theoretical approach, enabling the visualization of simple interactions of everyday life. The video shows several ordinary interactions, which are, little by little, graphically represented by their duration associated with body movement. The goal is to promote the awareness of physical interaction, duration and sensorial perception when creating new products and technologies.
\end{abstract}

Keywords: Interaction design, digital technologies, inteface design, tangibility, movement, subjectivity, visualization.

\section{Introduction}

If we wish to listen to music, we can use a small and delicate object that, plugged in our ears, allows us to have instantaneous access to thousands of different songs. If we wish to chat right now with a relative who is far away, we can take our mobile out of the pocket and, in a matter of seconds, this relative will take his phone out of his pocket too.

Physical interaction processes (what happens between wish and result) nearly vanish. The hurry is so that people get irritated if they have to make an extra click to complete a phone call. These processes don't get the chance of being pleasurable, because those who created them looked for their end, I mean, for results that could appear in the blink of an eye.

Such contemporary phenomena are being widely discussed lately, in books, movies, newspapers articles and even among internet users. Movements to criticize digital immediateness are getting attention but, unfortunately, these people are seen as luddites, or anti-technologic.

The goal of this critical design study [1, is to suggest an extra thinking about interactive processes. As metaphors of paths, these processes appear to us like choices. For a wish, we can take several different ways to achieve a result; some are long and demand time and attention; others are short, which we can call shortcuts. It takes more effort to cook in a traditional syle, instead of using a microwave; however, it is a much more engaging experience, and it becomes a pleasant moment of everyday life. 


\section{Real Time, Real Space}

In this video, four examples of ordinary interaction processes are chosen to illustrate this metaphor of shortcuts. A man selects a vinyl record to play; in the next scene, he is selecting an album in an iPod. A woman appears cooking next to a stove: then, this same woman puts some food in a microwave. A letter is waiting for its receiver in a mail box; the situation repeats, but in a digital context. Last, someone is looking for a picture in a drawer; this same person is, in the next scene, looking for a picure in a computer's folder. They appear in two different 'parallel realities', represented by two possible objects we can interact with: one understood as a long way, and another as a shortcut. Three of them are in communication media field, which are the focus of this study. Text, sound and image appear being accessed, each in two in different ways, by a same user; the scenes communicate a series of elements, intrinsic to the processes. These elements are both objective (duration, number of objects, dimensions and textures of objects, user's body movement) and subjective (joy, involvement, pleasure).

The presence of shortcuts pervades all moments in everyday life. When we have to accomplish trivial tasks, we tend to choose shorter and more practical ways to conclude them in the less time and effort possible. Besides situations with communication media, another example was added to the video: cooking. It is a pleasant process, one of the few that a lot of people agree that demand time and energy; we can interfere directly, reaching all mankind's five senses. It serves as a good example to suggest that values, such as duration, movement and sensorial perception, can be applied in other kinds of daily interaction. Especially those related to digital products, as they will soon face a time of deep changes.

In a near future, virtual information will be present in material objects and in real places. Interaction will, then, abandon a state of interface accessed through screens and buttons. The physical world will serve as support of information. Several technologies were already prepared for this reality, like the RFID (Radio Frequency Identity) and the NFT (Near Field Technology). Everyware, term created by Adam Greenfield, represents well what this new age of virtualiy means.

Hopefully, things won't have screens, nor keyboards. With the internet of things and places, we have to redesign the interactions with things and places. Therefore, the observation and analysis of everyday trivial movements, handles and gestures, with simple material objects, can give us hints to apply intuitive and spontaneous interactions to complex technologic demands.

Some progress has already been made in the direction of finding new humancomputer interfaces. Current mobiles, PDAs and mp3-players are getting elements adapted to their contexts. However, they're still far behind the ideal. Studies areas, called, for example, tangible media at MIT Media Lab, and physical computing at the Interactive Telecommunications Program of NYU, have the goal of combining the world of objects to the world of information: physical interfaces are developed for digital data manipulation. 


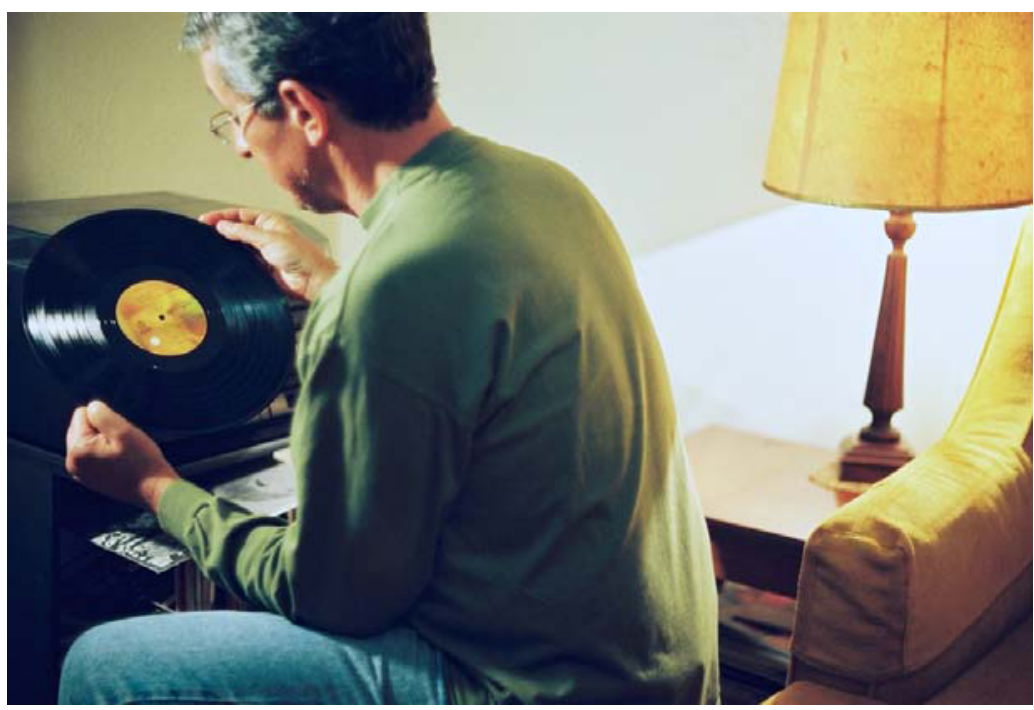

Fig. 1. The 'long way' interaction: duration, movement and sensorial perception are a strong part of the process

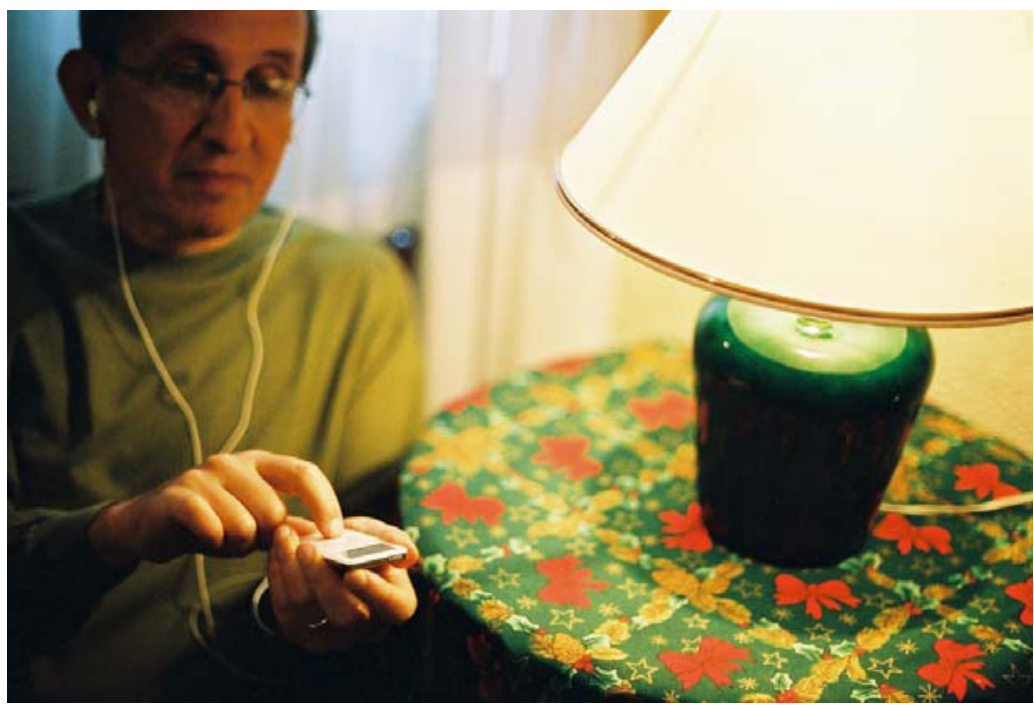

Fig. 2. The shortcut: simple actions for immediate results

\section{Conclusion}

The future of technology seems to be in the interaction with real things, and not in the immersion of a user in a virtual ambience, isolated, with no direct 
interference of the world around him. There are recent design projects that predict this tendency, for they consider users' experience in the real world - intuitive gestures for natural interfaces that don't need any explanatory manual to be used. Several articles in critical design are good examples [2], 3], to prove the importance and urgency of this subject. Besides, these works can guide research-throughdesign projects, serving as a basis to new paradigms in interaction design.

"A sensitively designed everyware will take careful note of the qualities our experiences derive from being situated in real space and time. The more we learn, the more we recognize that such cues are more than mere niceties - that they are, in fact, critical to the way we make sense of our interactions with one another." [4]

Real space and time: based on this statement, this video suggests that interactive processes can be visualized, by materializing traces of physical movement during the time these processes take. These traces become saturated in color as time goes by. In the end, all visualizations are put together: one image for the 'long ways', and another for the shortcuts. The last scene is a comparison of these two groups of traces, and reveals that we might miss something if we take shortcuts all the time.

Acknowledgments. I would like to thank the reviewers for their helpful comments and critics on this project, and suggestions of related academic work in the interaction design field. It has been my first try on presenting ideas outside the design school I've recently graduated. I also thank my supervisor, Prof. Silvia Steinberg, and my relatives and friends who worked as actors and composers for the video.

\section{References}

1. Dunne, A., Raby. F.: Design Noir: The Secret Life of Electronic Objects. Birkhser, Basel, Switzerland (2001)

2. Halln, L., Redstr, J.: Slow Technology Designing for Reflection, Personal and Ubiquitous Computing, vol. 5(3). ACM Press, New York (2001)

3. Hoven, E., van den Frens, J., Aliakseyeu, D., Martens, J.B., Overbeeke, K., Peters, P.: The expressive character of interaction: Design research \& tangible interaction. In: Proceedings of the 1st international conference on Tangible and embedded interaction TEI, ACM Press, New York (2007)

4. Greenfield, A.: Everyware - the dawning age of ubiquitous computing. New Riders, Berkeley 74 (2005) 